\title{
QUALIDADE DO EXAME BACILOSCÓPICO NO DISTRITO FEDERAL (BRASIL) - UMA AVERIGUAÇÃO DA CONFIABILIDADE
}

\author{
THE QUALITY OF THE BACILOSCOPIC TEST IN DISTRITO FEDERAL \\ (BRAZIL) - AN INQUIRY ABOUT ITS RELIABILITY \\ CALIDAD DEL EXAMEN BACILOSCÓPICO EN EL DISTRITO FEDERAL \\ (BRASIL) - UNA AVERIGUACIÓN DE LA CONFIABILIDAD
}

\author{
Maria do Socorro Evangelista Kusano' \\ Francisco Duarte Vieira ${ }^{2}$ \\ Ana Lúcia Atta Sarmento ${ }^{2}$ \\ Rosália Maia ${ }^{3}$
}

\begin{abstract}
RESUMO:No Brasil, uma das prioridades do plano de combate à tuberculose é a avaliação de desempenho laboratorial através do controle de qualidade das baciloscopias. Este estudo objetivou avaliar a confiabilidade dos exames realizadas pelo Programa de Tuberculose do Distrito Federal (PCT-DF). Trata-se de um estudo descritivo, realizado a partir das lâminas revisadas no laboratório de referência, de 1988 a 1999. Comparou-se em dupla cega os resultados das leituras dos esfregaços obtidos na periferia e laboratório central. As concordâncias/discordâncias foram analisadas pelo Kappa e intervalo de confiança (IC). Avaliaram-se 7.756 lâminas, obtendo-se discordâncias de 1,9\% de falso-positivas e de $0,8 \%$ falso-negativas. Até $1997,66,5 \%$ das baciloscopias positivas foram revisadas. Implementada essa atividade, atingiu-se 90,1\%. A confiabilidade foi ótima pelo Kappa, discordando com os resultados do IC. O controle de qualidade deve ampliar a confiabilidade do diagnóstico de tuberculose, entretanto, a avaliação depende do uso de testes de reprodutibilidade sensiveis.
\end{abstract}

PALAVRAS-CHAVE: controle de qualidade, confiabilidade, tuberculose

\section{INTRODUÇÃO}

A partir da década de 90 , o Brasil estabeleceu sucessivos planos de combate à tuberculose em função da emergência global desta enfermidade. Desde então, o programa nacional tem ampliado as estratégias de controle da doença, priorizando a extensão da cobertura, ativação da busca de caso, descentralização das ações e serviços e, como também, avaliando o desempenho dos laboratórios por meio do controle de qualidade das baciloscopias (BRASIL, 1999a, 1999b).

O controle baciloscópico é essencial tanto do ponto de vista individual quanto coletivo, pois permite um diagnóstico com perspectiva de tratamento, gerando uma importante repercussão familiar, econômica e social. O exame direto tem sido priorizado nas unidades de saúde, em função da sua simplicidade, rapidez e baixo custo (FERNANDEZ, 1996, BRASIL, 1994b). Sobretudo porque permite um diagnóstico de certeza, e determina o inicio do tratamento quimioterápico, vital na interrupção da cadeia de transmissão da tuberculose (BRASIL, 1994a,

\footnotetext{
1 Profa. Adjunto da Faculdade de Ciências da Saúde - Departamento de Enfermagem/UnB.

${ }^{2}$ Farmacêutico e Bióloga responsáveis pelo Laboratório de Referência de Tuberculose do Distrito Federal.

${ }^{3}$ Assessora técnica na área de laboratório do Programa Nacional de Tuberculose.
} 
VALENZUELA et al., sd).

Como a identificação do "caso" se baseia na investigação bacteriólogica entre os sintomáticos respiratórios, deve-se objetivar a melhoria do diagnóstico através do uso de tecnologias mais sensiveis, monitoramento da qualidade e rendimento do esfregaço (OMS, 1994). Considerando que esta atividade transcende ao diagnóstico, deve-se garantir a confiabilidade dos exames, principalmente neste momento de descentralização dos serviços e priorização da atividade pelo programa nacional (BRASIL, 1999a).

O Ministério da Saúde tem estabelecido a supervisão direta e indireta na atividade do diagnóstico bacteriológico. A direta, refere-se à visita do supervisor ao serviço para avaliar os exames baciloscópicos na unidade de saúde. Enquanto a indireta, permite uma supervisão à distância, e consiste na remessa das baciloscopias ao laboratório de referência para releitura (BRASIL, 1994a). Esta avaliação analisa as concordâncias e discordâncias dos esfregaços, muito importante do ponto de vista do diagnóstico e tratamento, por exigir, às vezes, revisão de ambos. Nas discordâncias falso-positivas, os principais fatores responsáveis por esse tipo de erro são fatores como: partículas de alimentos, manchas precipitadas, bacilos saprófitas resistentes aos ácidos, outras micobactérias não tuberculosas, esporos de bacillus subtilis, fibras e pólen, além de riscos na lâminas. Os resultados falso-negativos decorrem geralmente de deficiências na execução do esfregaço, na coloração e observação da lâmina, além da colheita e conservação inadequada do exame (WHO, 1974, TOMAN, 1980).

Este estudo tem por objetivo analisar a confiabilidade dos exames baciloscópicos realizados pelos laboratórios do PCT-DF, através de dois métodos de avaliação. Por outro lado, levanta uma discussão a respeito da importância do tema e a necessidade de implementação desta atividade em todo pais, por ser fundamental para o Programa de Controle da Tuberculose.

\section{MÉTODO}

Brasilia, Distrito Federal, Capital da República, situa-se na região Centro-Oeste do Brasil. Possui uma área territorial de $5.814 \mathrm{Km}^{2}$, faz limite com os estados de Goiás, envolvendo-o quase que completamente, excetuando-se o Sudeste que faz limite com Minas Gerais. Encontrase dividido em 19 Regiões Administrativas (RA) e possui uma população estimada em dois milhões de habitantes (CODEPLAN, 1999). O Programa de Controle da Tuberculose do Distrito Federal (PCT-DF) deu início às suas atividades em 1958, durante a construção da cidade de Brasilia. Desde 1979, o Sistema de Saúde no Distrito Federal encontra-se regionalizado e hierarquizado e a rede pública responde por quase $70 \%$ da atenção prestada. Ressalte-se que o doente tuberculoso é atendido, predominantemente, pelos serviços estatais, uma vez que o esquema específico é de uso exclusivo do programa.

Trata-se de um estudo descritivo, cujos dados foram coletados no Laboratório de Referência do PCT-DF, órgão ligado à Secretaria de Saúde, responsável pelo registro e revisão das baciloscopias do Estado. A coleta de dados foi efetuada entre maio e junho de 2000.

O Laboratório de Referência do PCT-DF, até 1988, seguiu as normas nacionais que orientava a revisão mensal de $100 \%$ das lâminas positivas e $10 \%$ das negativas (BRASIL, 1994). Em 1999, o PCT-DF elaborou um projeto de implementação dessa atividade nos laboratórios, juntamente com o representante da Organização Panamericana de Saúde (DISTRITO FEDERAL, 1999), reorientando as instruções para revisão das baciloscopias, apresentadas a seguir:

- Laboratórios que realizam menos de 10 baciloscopias em média mensal (menos de 120 baciloscopias ao ano), conservar todas as lâminas, positivas e negativas;

- Laboratórios que efetuam entre 10 a 15 baciloscopias em média mensal (120 a 600 baciloscopias ao ano), conservar todas as lâminas positivas e as 3 (três) negativas seguintes a uma positiva. Caso um laboratório não encontre lâminas positivas, deve conservar um mínimo 
de 5 lâminas negativas mensais com numerações seguidas;

- Laboratórios que realizam mais de 50 baciloscopias em média mensal (maior que 600 baciloscopias ao ano), conservar todas as positivas e as duas lâminas negativas seguintes a uma positiva, se encontrar 2 (duas) lâminas positivas seguidas, conservar 4 (quatro) negativas seguintes.

Na releitura das lâminas foram utilizados os mesmos critérios da primeira leitura (DISTRITO FEDERAL, 1999). Vale ressaltar que todos os exames foram mensalmente identificados nos laboratórios locais/regionais e enviados trimestralmente à referência, relacionando-se a finalidade e o resultado da observação. No laboratório do PCT-DF, procedeu-se à revisão dos exames em dupla cega e, em seguida, comparados os resultados.

Para classificação das concordâncias e discordâncias, foram empregadas as seguintes fórmulas (BRASIL, 1994a):

Falso-positivo $=\frac{\text { Fp } \times 100}{\text { Total de lâminas comparadas }}$

Falso-negativo $=\frac{\text { Fn } \times 100}{\text { Total de lâminas comparadas }}$

Concordâncias $=\frac{\mathrm{Vp}+\mathrm{Vn} \times 100}{\text { Total de lâminas comparadas }}$

Sendo: $F p=$ falso-positivo, $F n=$ falso-negativo e $V p=$ verdadeiros-positivos e $V n=$ verdadeiros-negativos.

Caracterizando-se como:

- falso-negativo: quando o exame foi positivo no laboratório de referência e negativo no laboratório de origem;

- falso-positivo: quando a baciloscopia foi negativa no laboratório de referência e positivo no laboratório local (BRASIL, 1994a).

Foi analisada a freqüência da remessa das lâminas por unidade laboratorial, assim como o cumprimento das normas de seleção dos esfregaços e a planilha global dos exames realizados nos laboratórios do programa. Também, observou-se a confecção das lâminas e sua coloração, bem como as caracteristicas do escarro.

Para estimar a reprodutibilidade dos exames, utilizou-se o indicador chamado Kappa (PEREIRA, 1995) e, além disso, empregou-se o teste estatístico do qui-quadrado.

Para se obter o intervalo de confiança $(M O O D, 1974)$ dessas proporções, utilizou-se a expressão:

$P\left[p_{i}<p<p_{s}\right]=1-a$

Sendo,

$$
p_{i}=\frac{2 a+z_{\frac{\alpha}{2}}^{2}-d}{2\left(n+z_{\frac{\alpha}{2}}^{2}\right)}
$$




$$
\begin{aligned}
& p_{s}=\frac{2 a+z_{\frac{\alpha}{2}}^{2}+d}{2\left(n+z_{\frac{\alpha}{2}}^{2}\right)} \\
& d=z_{\frac{\alpha}{2}} \sqrt{z_{\frac{\alpha}{2}}^{2}+4 a\left(1-\frac{a}{n}\right)}
\end{aligned}
$$

Sendoa = o número de ocorrências (positivo e negativo) no nivel regional/local;

$\mathrm{n}=\mathrm{o}$ número total de ocorrências (positivo ou negativo) na referência;

$\mathrm{p}_{\mathrm{i}}=$ limite inferior da proporção

$\mathrm{p}_{\mathrm{s}}=$ limite superior da proporção

$\alpha=$ o nivel de significância

$z \frac{\alpha}{2}=$ a abscissa da curva normal padrão $\mathrm{N}(0,1)$, correspondente a área $\frac{\alpha}{2}$ em cada cauda da distribuição (MOOD, 1974). Considerou-se a $=5 \%$ e $z \frac{\alpha}{2}=1,96$.

\section{RESULTADOSE DISCUSSÃO}

Foram analisadas, neste estudo, 7.756 baciloscopias enviadas para o controle de qualidade, das 62.591 lâminas realizadas pelos 15 laboratórios do programa. Constatou-se que entre 1988 e 1997, apesar da obrigatoriedade mensal do envio das lâminas para releitura, foram encaminhados, em média, os esfregaços de quatro meses por ano. A partir de 1998, com a reestruturação dos laboratórios de tuberculose na região Centro-Oeste, ampliou-se a cobertura e observou-se, em média, um envio em torno de seis meses/ano. É provável que os laboratórios emitiram relatórios agregados e, portanto, o sub-registro mensal das informaçōes. Na avaliação por laboratório, a regional de Taguatinga foi a que apresentou maior regularidade quanto à remessa das informações à referência. A regional do Gama entretanto, respondeu pelo maior número de lâminas revisadas no laboratório do PCT-DF (2.025/7.756).

Com relação ao total de lâminas enviadas para supervisão indireta até 1997, a média anual de releitura atingiu $66,5 \%$ das lâminas positivas e $10,8 \%$ das negativas. A remessa, porém, dos exames baciloscópicos negativos, em 1988 (de 19,0\%) e, principalmente, em 1994 (com 39,5\%), foram os responsáveis pela elevação global da série histórica analisada. A orientação proposta era uma revisão de $100 \%$ das bacterioscopias positivas e $10 \%$ das negativas (BRASIL, 1994a). De fato, nos dez primeiros anos do estudo, sete deles tiveram seus percentuais abaixo dos parâmetros estabelecidos pelo Ministério da Saúde, superando-os em apenas três anos. Em função da restruturação do controle de qualidade e o emprego de novos critérios de seleção dos exames nos laboratórios do Distrito Federal, entre 1998-99, houve uma ampliação da releitura das lâminas positivas superior a $90 \%$ e, de $12,2 \%$ das negativas.

A análise do periodo em sua totalidade apresenta uma remessa de exames positivos em torno de $72,3 \%(2.700 / 3.735)$ e, negativos, de $8,6 \%(5.056 / 58.856)$; porém, ambas as taxas estão abaixo do padrão permitido pelo Ministério da Saúde. Esta avaliação global traz implicação 
direta para o diagnóstico emitido pelo serviço de tuberculose local, uma vez que o "caso" identificado baseou-se no resultado do exame direto. É óbvio que a grande maioria das baciloscopias positivas e negativas foram submetidas à releitura, entretanto, parte delas não foram (GRÁFICO 1).

Alguns obstáculos interferem na efetivação dessa atividade pelo programa do Distrito Federal. Dentre eles, estão: falta uniformidade no registro dos resultados das lâminas (regional/ nacional), sistema de informação com duplo registro (Ministério da Saúde/Livro Interno do Serviço), anotação dos dados de forma manual, assim como, falta de sensibilização dos profissionais envolvidos no projeto. Este fator deve gerar vieses, especialmente, em relação à seleção de lâminas, dificultando assim, a avaliação global das bacterioscopias a serem processadas na referência. Por outro lado, emerge a necessidade de um registro mensal de notificação negativa pelos laboratórios locais, evitando ocultar falha de informação mensal nas unidades de pequeno porte.

\section{GRÁFICO 1 - PERCENTUAL DE LÂMINAS POSITIVAS E NEGATIVAS CONSERVADAS PARA A RELEITURA, NO LABORATÓRIO DO PCT - DF, 1988 - 1999}

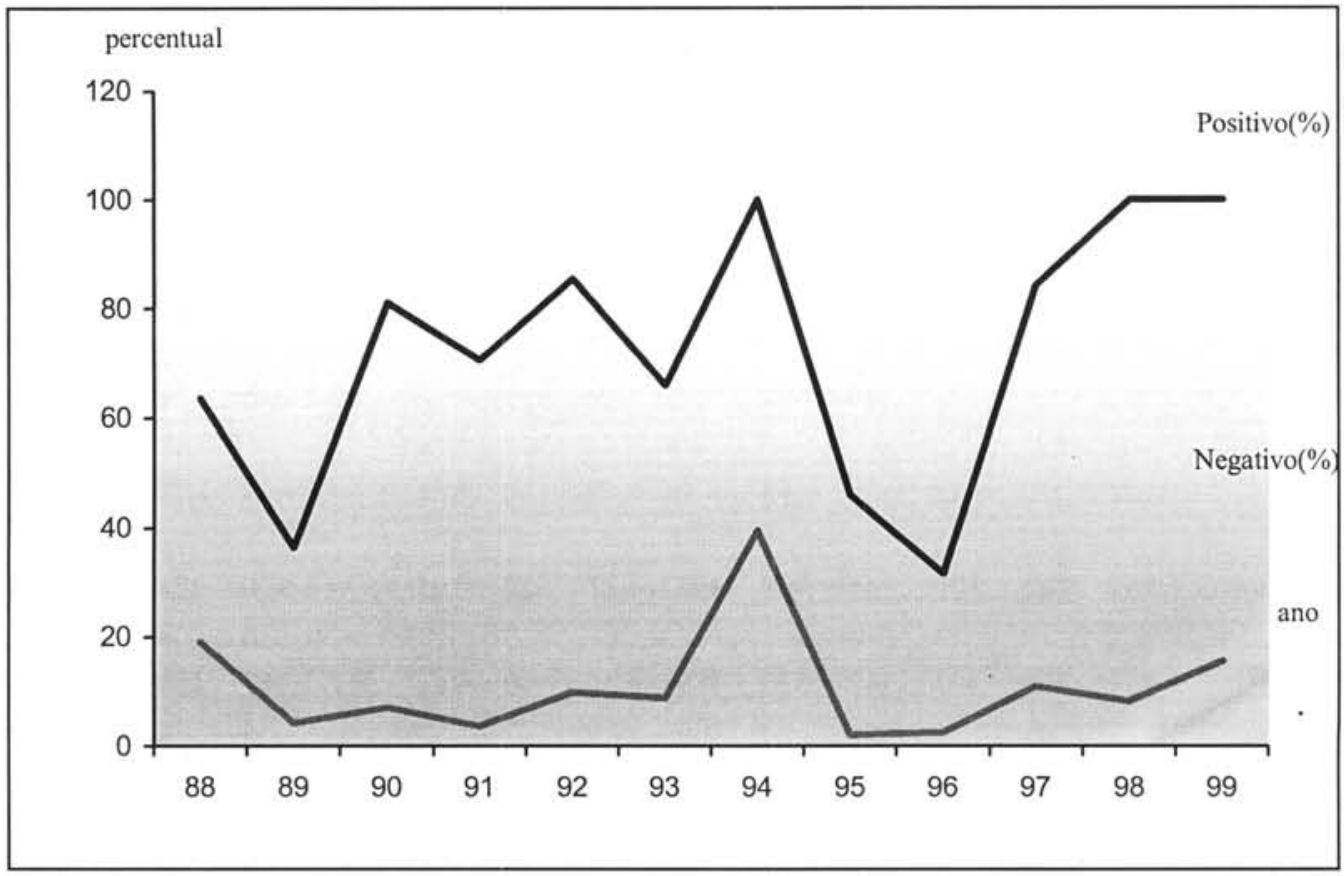

O gráfico 1 demonstra que entre 1988 e 1999, conservou-se um total de 2.700 lâminas positivas para o controle de qualidade, com uma discordância média de 1,9\%. Dentre as 5.056 baciloscopias negativas examinadas, verificou-se um erro de $0,8 \%$, sendo que a média total de discordâncias ficou em 1,2\%. Cabe salientar que a inobservância de erros nos anos de $1989 \mathrm{e}$ 1995, é discutivel (Tabela 1). Bem como, os exames realizados nos anos de 1991 (B+), 1993 e 1994 (B-). Segundo a Organização Mundial da Saúde, o parâmetro estabelecido como aceitável é de até $1 \%$, tanto para as discordâncias falso-positivas, como para as falso-negativas (BRASIL, 1988, PERU, 1996). Pode-se constatar que o programa local alcançou o padrão permitido somente para as discordâncias negativas. Quando comparado com o programa peruano, entre 1993-97, o erro global médio observado foi de 0,6\%, sendo que em 1997, estas discordâncias atingiram 0,2\% (PERU, 1997). 
Qualidade do exame baciloscópico...

TABELA 1 - RESULTADOS DAS LÂMINAS SUBMETIDAS AO CONTROLE DE QUALIDADE DO PCT-DF, 1988 - 1999

\begin{tabular}{|c|c|c|c|c|c|c|c|c|c|c|c|c|c|}
\hline \multirow{2}{*}{ VARIÁVEIS } & \multicolumn{12}{|c|}{ ANO } & \multirow{2}{*}{ Total } \\
\hline & 88 & 89 & 90 & 91 & 92 & 93 & 94 & 95 & 96 & 97 & 98 & 99 & \\
\hline \multicolumn{14}{|l|}{ BK positivos } \\
\hline $\begin{array}{l}\mathrm{BK}(+) \\
\text { realizados }\end{array}$ & 133 & 81 & 173 & 178 & 283 & 214 & 242 & 196 & 104 & 316 & 437 & 343 & 2700 \\
\hline $\begin{array}{l}\mathrm{BK}(+) \\
\text { concordantes }\end{array}$ & 132 & 81 & 172 & 178 & 279 & 210 & 241 & 196 & 103 & 303 & 413 & 340 & 2648 \\
\hline$(\%)$ & 99,2 & 100 & 99,4 & 100 & 98,5 & 98,1 & 99,5 & 100 & 99,0 & 95,8 & 94,5 & 99,1 & 98,08 \\
\hline & 5 & & 2 & & 9 & 3 & 9 & & 4 & 9 & 1 & 3 & \\
\hline $\begin{array}{l}\mathrm{BK}(+) \\
\text { discordantes }\end{array}$ & 1 & 0 & 1 & 0 & 4 & 4 & 1 & 0 & 1 & 13 & 24 & 3 & 52 \\
\hline $\begin{array}{c}(\%) \\
\text { BK negativos }\end{array}$ & 0,75 & 0 & 0,57 & 0 & 1,41 & 1,87 & 0,41 & 0 & 0,96 & 4,11 & 5,49 & 0,87 & 1,92 \\
\hline $\mathrm{BK}(-)$ realizados & 324 & 160 & 206 & 167 & 312 & 279 & 380 & 154 & 191 & 613 & 769 & $\begin{array}{r}150 \\
1\end{array}$ & 5056 \\
\hline $\begin{array}{l}\text { BK( (-) } \\
\text { concordantes }\end{array}$ & 322 & 160 & 205 & 164 & 311 & 279 & 380 & 154 & 189 & 608 & 761 & $\begin{array}{r}148 \\
2\end{array}$ & 5015 \\
\hline$(\%)$ & 99,3 & 100 & 99,5 & 98,2 & 99,6 & 100 & 100 & 100 & 98,9 & 99,1 & 98,9 & 98,7 & 99,19 \\
\hline & 8 & & 1 & & 8 & & & & 5 & 9 & 6 & 4 & \\
\hline $\begin{array}{l}\mathrm{BK}(-) \\
\text { discordantes }\end{array}$ & 2 & 0 & 1 & 3 & 1 & 0 & 0 & 0 & 2 & 5 & 8 & 19 & 41 \\
\hline $\begin{array}{c}(\%) \\
\text { Total de BK } \\
\end{array}$ & 0,62 & 0 & 0,48 & 1,79 & 0,32 & 0 & 0 & 0 & 1,05 & 0,81 & 1,04 & 1,26 & 0,81 \\
\hline BK realizados & 457 & 241 & 379 & 345 & 595 & 493 & 622 & 350 & 295 & 929 & $\begin{array}{r}120 \\
6\end{array}$ & $\begin{array}{r}184 \\
4\end{array}$ & 7756 \\
\hline BK & 454 & 241 & 377 & 342 & 590 & 489 & 621 & 350 & 292 & 911 & 117 & 182 & 7663 \\
\hline concordantes & & & & & & & & & & & 4 & 2 & \\
\hline$(\%)$ & 99,3 & 100 & 99,4 & 99,1 & 99,1 & 99,1 & 99,8 & 100 & 98,9 & 98,0 & 97,3 & 99,8 & 98,8 \\
\hline & 5 & & 7 & 4 & 6 & 9 & 4 & & 8 & 6 & 5 & 1 & \\
\hline BK discordantes & 3 & 0 & 2 & 3 & 5 & 4 & 1 & 0 & 3 & 18 & 32 & 22 & 93 \\
\hline$(\%)$ & 0,65 & 0 & 0,52 & 0,86 & 0,84 & 0,81 & 0,16 & 0 & 1,02 & 1,94 & 2,65 & 1,19 & 1,20 \\
\hline
\end{tabular}

O PCT-DF apresentou em 1997, um percentual de erros falso-positivos em torno de $4,1 \%$ e falso-negativos de $0,8 \%$. No mesmo periodo, estas discordâncias no Peru, atingiram $0,6 \%$ e $0,1 \%$, respectivamente. Os fatores operacionais de maior interferência nos laboratórios do PCT-DF foram: falha na supervisão direta e indireta no sistema de registro dos dados, dificuldades na criação de estratégias para atingir as metas (tanto na referência como na regional), dificuldade na avaliação anual do controle de qualidade e a não informatização dos dados laboratoriais. A concordância global obtida nesse estudo alcançou 98,8\%. No entanto, Jekel (1999) e Pereira (1995) consideram este parâmetro de avaliação inadequado e de pouca importância prática. 
GRÁFICO 2 - CONTROLE DE QUALIDADEDAS BACILOSCOPIAS -DISCORDÂNCIA TOTAL, FALSO(+) E FALSO (-) NO PCT-DF, 1988 - 1999.

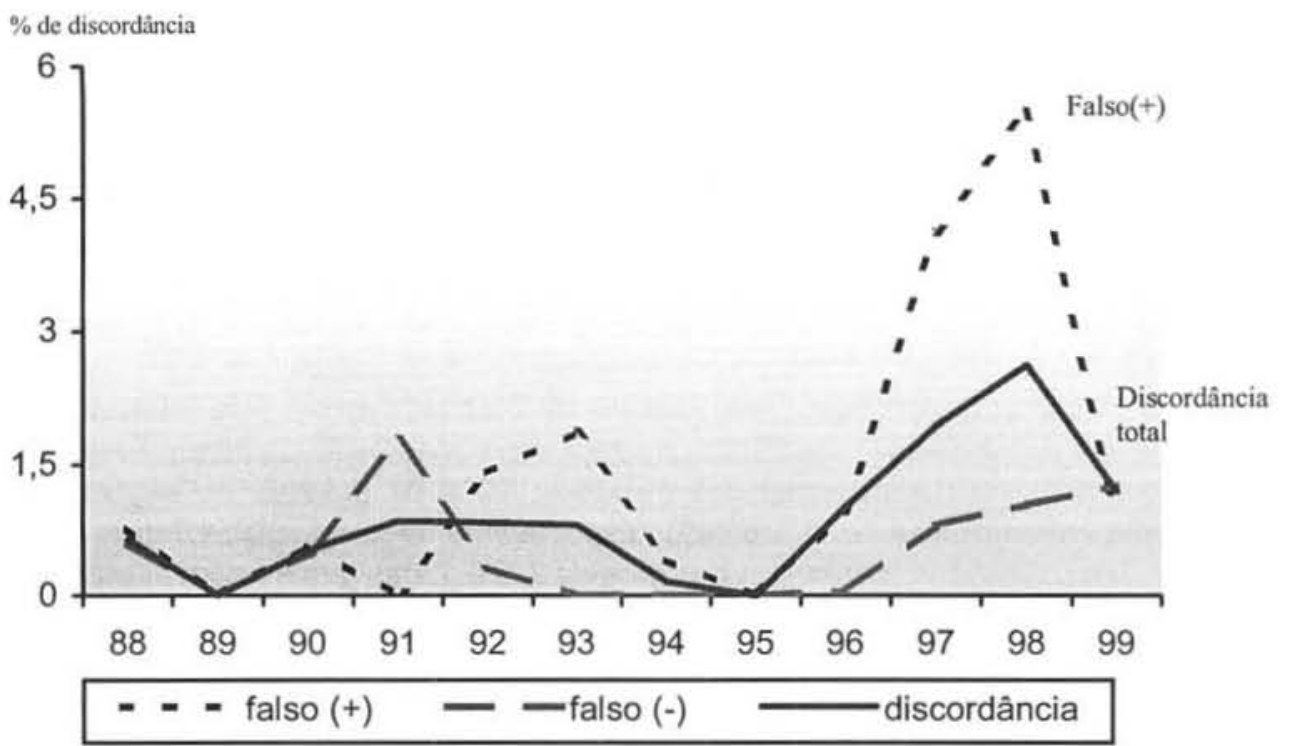

O gráfico 2 mostra as discordâncias falso-positivas e negativas no periodo em estudo, variando de 0,4 a $5,5 \%$ e, de 0,3 a $1,8 \%$, respectivamente. Foi encontrado em média, $1,2 \%$ de falso (+) e $0,6 \%$ de exames falso (-). O que se observa em relação a estas variáveis é uma nitida flutuação dessas taxas no tempo, fato pouco comum nas áreas onde o controle de qualidade está sendo aplicado de forma rigorosa e permanente. Como exemplo, temos as avaliaçōes dos programas chilenos e peruanos, que se caracterizam por regularidade nos resultados; além disso, estes registram uma queda desses indices no tempo (PERU, 1996, PERU, 1997. VALENZUELA, sd).

\section{GRÁFICO 3 -PERCENTUAL DE DISCORDÂNCIANO CONTROLE DE QUALIDADE DAS BACI- LOSCOPIAS REALIZADAS PELO PCT-DF, 1988-97 - 1998-99}

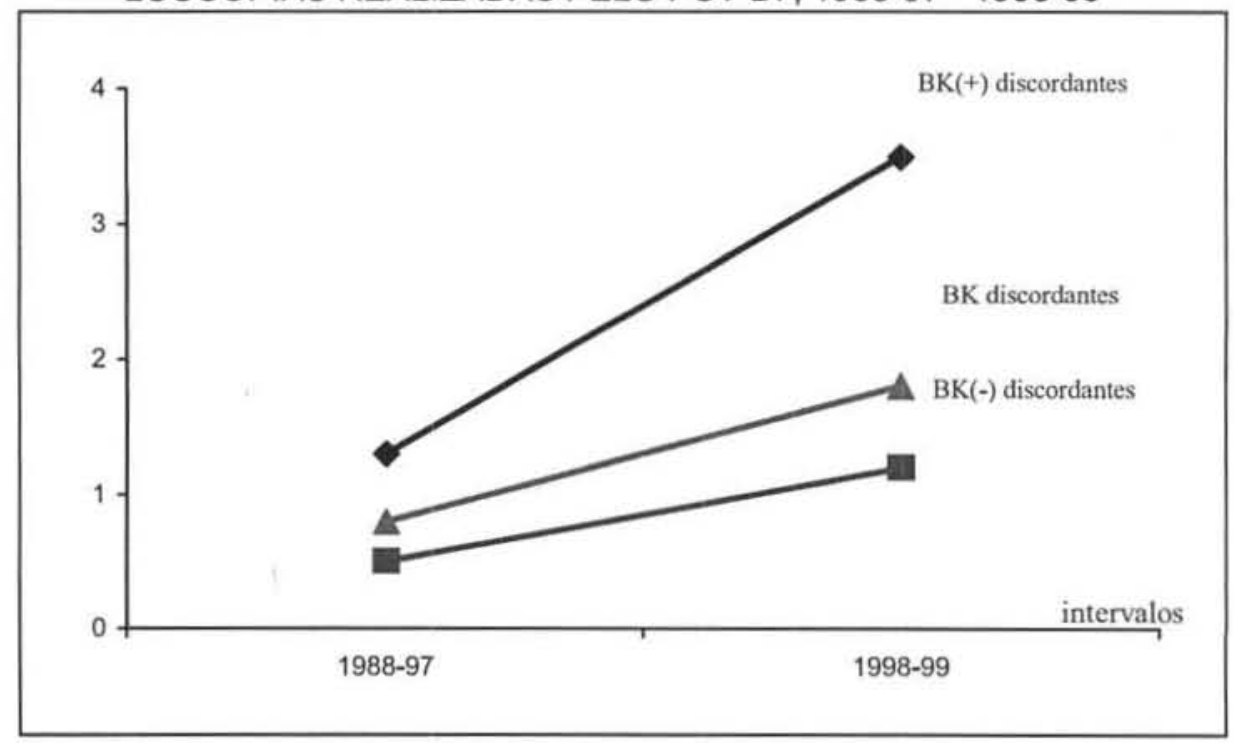


No gráfico 3 foram comparadas as divergências antes (1988-97) e depois (1998-99) da implementação do controle de qualidade nos laboratórios do programa. Observou-se um incremento das discordâncias de um intervalo a outro, com maior elevação no último período. Coincidentemente, este último incremento correspondeu à fase de restruturaçäo do programa, onde as pessoas envolvidas no processo de aferição, seja o observador ou o observado, foram treinadas; novos equipamentos microscópios foram colocados à disposição nas unidades de saúde; intensificaram-se as supervisões e, além disso, as lâminas sofreram melhor seleção no local de origem, levando, provavelmente, a uma leitura mais acurada. É também provável, que existisse uma ocultação de erros e, com uma melhor averiguação dos exames, agora, eles recrudeceram. Ambas discordâncias falso-positivas e negativas trazem conseqüências, porque implicam em erro no diagnóstico e na indicação de tratamento de tuberculose, sendo que a discordância falso-positiva é considerada a mais grave (BRASIL, 1994a).

Para estimar a reprodutibilidade dos exames na totalidade do periodo, aplicou-se o teste de Kappa e o valor encontrado foi de 99,5\%, ou seja, uma concordância ótima. Empregou-se, também, o mesmo teste para análise dos periodos: 1988-97 e 1998-99, separadamente, resultando numa concordância de $96 \%$ e $94 \%$, respectivamente. Em seguida, foram realizadas várias simulações utilizando-se os dados das tabelas 2,3 e 4, nas quais foram alterados o total de casos em determinadas células, sendo identificadas algumas dificuldades na interpretação dos resultados, as quais apresentamos a seguir:

- a verificação de um grande número de concordantes na categoria - negativa em relação à positiva, parece que está indevidamente elevando a taxa de concordância da amostra;

- a discordância observada entre os resultados positivos e negativos, não mostra como foram distribuidos os erros entre os observadores, se um obteve maior número de acertos que o outro, se foram distribuidos uniformemente ou se ambos erraram. O esperado é que o leitor padrão do laboratório de referência não tenha cometido erro.

Considerando-se a problemática, analisou-se cada categoria de variável individualmente, procurando-se obter o intervalo de confiança dessas proporções, nos periodos (1988-97; 199899 e 1988-99), como mostram as tabelas 2,3 e 4.

TABELA 2 - RESULTADOS DOS EXAMESBACILOSCÓPICOS REALIZADOS PELAREFERÊNCIA DO PCT-DF E LABORATÓRIO REGIONAL/LOCAL, 1988 - 1997

\begin{tabular}{rccr}
\hline \multirow{2}{*}{ Lab. Referência } & \multicolumn{2}{c}{ Lab. Regional e Local } & \\
\cline { 2 - 3 } Positivo & 1895 & Negativo & \multirow{2}{*}{ Total } \\
& $(\mathrm{IC}=98,1-99,1 \%)^{*}$ & $(\mathrm{IC}=0,9-1,9 \%)^{*}$ & \\
Negativo & 14 & 2772 & 27820 \\
& $(\mathrm{IC}=0,3-0,8 \%)^{*}$ & $(\mathrm{IC}=99,2-99,7 \%)^{*}$ & \\
& & &
\end{tabular}

* Foi considerado o resultado obtido no laboratório de referência. Kappa $=96 \%$. 
KUSANO, Maria do Socorro Evangelista et al.

TABELA 3-RESULTADOS DOS EXAMES BACILOSCÓPICOS REALIZADOS PELA REFERÊNCIA DO PCT-DF E LABORATÓRIO REGIONAL/LOCAL, 1998 - 1999

\begin{tabular}{rccc}
\hline \multirow{2}{*}{ Lab. Referência } & \multicolumn{2}{c}{ Lab. Regional e Local } & \multirow{2}{*}{ Total } \\
\cline { 2 - 3 } Positivo & 753 & Negativo & 27 \\
& & & 780 \\
& & & \\
Negativo & 27 & 2243 & 2270 \\
& $(\mathrm{IC}=0,8-1,7 \%)^{*}$ & $(\mathrm{IC}=98,3-99,2 \%)$ & \\
\hline
\end{tabular}

* Foi considerado o resultado obtido no laboratório de referência. Kappa $=94 \%$.

TABELA 4 - RESULTADOS DOS EXAMESBACILOSCÓPICOS REALIZADOS PELA REFERÊNCIA DO PCT-DF E LABORATÓRIO REGIONAL/LOCAL, 1988 - 1999

\begin{tabular}{|c|c|c|c|}
\hline \multirow[b]{2}{*}{ Lab. Referência } & \multicolumn{2}{|c|}{ Lab. Regional e Local } & \multirow[b]{2}{*}{ Total } \\
\hline & Positivo & Negativo & \\
\hline Positivo & $\begin{array}{c}2648 \\
(\mathrm{IC}=97,5-98,5 \%)^{*}\end{array}$ & $\begin{array}{c}52 \\
(\mathrm{IC}=1,5-2,5 \%)^{*}\end{array}$ & 2700 \\
\hline Negativo & $\begin{array}{c}41 \\
(\mathrm{IC}=0,6-1,1 \%)^{*}\end{array}$ & $\begin{array}{c}5015 \\
(\mathrm{IC}=98,9-99,4 \%)^{*}\end{array}$ & 5056 \\
\hline
\end{tabular}

* Foi considerado o resultado obtido no laboratório de referência. Kappa= 99,5\%.

No periodo 1998-99, foi obtida a maior diferença estatística dos exames falso-negativos, com um intervalo de confiança de $95 \%$, entre $2,4 \%<p<5 \%$ (Tabela 3 ). Por outro lado, apesar do Kappa concordar em $99,5 \%$ no periodo 1988 a 1999, quando aplicado o intervalo de confiança, admite-se um erro de até $2,5 \%$ entre as baciloscopias falso-negativas (Tabela 4). Outra célula aponta um erro no máximo de 1,9\% (IC) de 1988 a 1997 entre as lâminas falso-negativas, enquanto o Kappa concorda em $96 \%$ (Tabela 2). Portanto, visualizam-se algumas discrepâncias nos resultados obtidos, após aplicação dos dois modelos de avaliação. O uso de intervalo de confiança parece discriminar mais adequadamente os erros e acertos, como também, pontua a célula de ocorrência do fenômeno. Verificou-se também, que uma dupla leitura (no periodo 1998-99) da mesma lâmina no laboratório de referência poderia diminuir a margem de erro, aproximadamente, de $r=0,05$ para $r=0,0025$, ou seja, uma redução de $5 / 100$ para $25 / 10.000$ lâminas lidas, o que representa uma queda bastante expressiva.

Quando comparado o total de lâminas enviadas para supervisão indireta, no periodo de 1988-97 e 1998-99, este número aumentou consideravelmente nos dois últimos anos. Foram examinadas 1.920 lâminas positivas no primeiro intervalo contra 780 no último. Noventa porcento dos esfregaços positivos realizados no Distrito Federal, entre 1998 e 1999 foram revisados. Quanto à releitura dos exames negativos, estes somaram 2.786, entre 1988 e 1997 e, posteriormente, 2.270 lâminas. A totalidade de lâminas submetidas ao teste de confiabilidade variou de 4.706 , nos primeiros 10 anos, para 3.050 , nos dois últimos anos. Foi testada a hipótese nula $\left(\mathrm{H}_{\mathrm{o}}\right)$, de que a proporção de concordantes e discordantes nos dois intervalos (1988-97 e 1998-99) é homogênea. Após cálculos, foram observadas diferenças estatisticamente significantes nas discordâncias a favor do último intervalo, ou seja, $14,444>c^{2}{ }_{1: 0,05}=3,8416$.

Enfim, os achados do presente trabalho mostram que é baixo o percentual de baciloscopias 
encaminhadas para o controle de qualidade, apesar do incremento dessa atividade nos dois últimos anos. Assinala-se, também, a existência de uma flutuação nas discordâncias falsopositivas e negativas no tempo, sem visualização de uma tendência de queda desses indices, diferentemente do que ocorre em programas bem estruturados como do Chile e Peru. A avaliação da confiabialidade expressa pelo valor de Kappa, foi ótima em todos os periodos analisados. Entretanto, ao utilizar o intervalo de confiança, ficou evidente uma discrepância nos resultados obtidos pelos dois modelos estatisticos.

A partir destas constatações, é possivel sugerir que os laboratórios de apoio ao programa de tuberculose do Distrito Federal incorporem esta atividade na rotina de organização dos serviços e, principalmente, incrementem o treinamento de pessoal como forma de assegurar a confiabilidade do diagnóstico de tuberculose. Além disso, deve-se garantir a melhoria na seleção e monitorização das lâminas, através da análise permanente e emprego de modelos estatísticos adequados.

ABSTRACT: In Brazil, one of the priorities in the fight against the tuberculosis is the evaluation of laboratories' performance through the quality control of baciloscopic tests. This study was meant to evaluate the reliability of the tests carried out by the Tuberculosis Control Program of the Federal District, Brazil. It is a descriptive study, made out of revised glass slides at the reference laboratory, from 1988 up to 1999. A double-blind comparison of the results of the smear readings obtained in the outskirts and central laboratories was made. The concordances/discrepancies were analyzed through Kappa and the Confidence Interval $(\mathrm{Cl})$. From a total of 62,487 glass slides, we evaluated 7,756 baciloscopic tests. The discrepancy results represented $1.9 \%$ of false-positive and $0.8 \%$ of falsenegative. Until 1997, $66.5 \%$ of the positive baciloscopic tests had been revised, but when the quality control was implemented the results grew up to $90.1 \%$. The Kappa obtained a very good reliability but didn't match with the $\mathrm{Cl}$ results. The quality control will increase the reliability of the tuberculosis diagnose although the evaluation depends on the use of sensitive reproducing tests.

KEYWORDS:quality control, reliability, tuberculosis

RESUMEN: Una de las prioridades del plan de combate a la tuberculosis en Brasil es la evaluación del desempeño laboratorial a través del control de calidad de las baciloscopias. Este estudio tuvo como finalidad evaluar la confiabilidad de los exámenes realizados por el programa de tuberculosis del Distrito Federal (PCT-DF). Se trata de un estudio descriptivo realizado a partir de láminas del laboratorio de referencia, de 1988 a 1999. Los resultados de las lecturas en laboratorios de los suburbios y en el laboratorio central se compararon. Las coincidenciasldivergencias fueron analizadas por los métodos Kappa e intérvalo de confianza (IC). Se evaluaron 7.756 láminas, obteniéndose divergencias del 1,9\% falso-positivas y del 0,8\% falso-negativas. Hasta $1997,66,5 \%$ de las baciloscopias positivas se revisaron. Implementándose esa actividad-recurso se alcanzó el $90,1 \%$. La confiabilidad fue excelente por el Kappa, contrariando los resultados del IC. EI control de calidad debe ampliar la confiabilidad del diagnóstico de la tuberculosis, sin embargo, la evaluación depende del uso de tests de sensibilidad reproductiva.

PALABRAS-CLAVE: control de calidad, confiabilidad, tuberculosis

\section{REFERÊNCIAS BIBLIOGRÁFICAS}

BRASIL. Fundação Nacional de Saúde. Centro Nacional de Epidemiologia. Coordenação Nacional de Pneumologia Sanitária. Centro de Referência Professor Hélio Fraga. Bol. de Pneumol. Sanit., Rio de Janeiro, v.7, n.2, jul./dez. p.52-57. 1999 b. 
- Ministério da Saúde. Fundação Nacional de Saúde. Plano Nacional de Controle da Tuberculose, Brasilia, 1999a.

- Ministério da Saủde. Secretaria Nacional de Programas Especiais de Saúde. Divisão de Pneumologia Sanitária. Campanha Nacional contra a Tuberculose. Coordenação de Pneumologia Sanitária, Centro de Referência Prof. Hélio Fraga. Controle da tuberculose: uma proposta de integração ensino-serviço. 4. ed. Brasilia, 1994b. 155p.

- Ministério da Saúde. Fundação Nacional da Saúde. Centro Nacional de Epidemiologia. Centro de Referência Prof. Hélio Fraga. Manual de bacteriologia da tuberculose, Rio de Janeiro. 1994a. 115p.

CODEPLAN. GDF. População por Região Administrativa: DF. Brasilia, 1999. Apresentado como folder.

DISTRITO FEDERAL. (BRASIL). Secretaria de Saúde. Instituto de Saúde do Distrito Federal. Instrutivo e protocolo de controle de qualidade, Circular n. 1. Brasilia, jan. 1999. 3p.

FERNANDEZ, H.R. Localización de casos y recursos de la red de laboratorios en el programa de control de la tuberculosis. Revista Argentina del Tórax, v.57, n.1/4, p.33-41, 1996.

JEKEL,J.F.; ELMORE, J.G.; KATZ, D.L. Concordância na aferição. Epidemiologia, bioestatística e medicina preventiva. São Paulo: Artmed, 1999. p.109-112.

MOOD, A. M., GRAYBILL, F. A., BOES, D. C. Introduction of theory of statistics. 3.ed. New York: McGrawHill, 1974.

ORGANIZAÇĀO MUNDIAL DA SAŨDE. Ministério da Saúde. Revisão do programa contra tuberculose. Brasilia, jul. 1994. (versão preliminar).

PEREIRA, M. G. Aferição de eventos. In: Guanabara Koogan, 1995. p.358-76. . Epidemiologia Teoria e Prática. Rio de Janeiro:

PERU. Ministerio de Salud. Dirección general de salud de la personas. Programa Nacional de Control de la Tuberculosis. Lima, 1996.

PERU. Ministerio de Salud. Dirección general de salud de la personas. Programa Nacional de Control de la Tuberculosis. Lima, 1997. p.59-68.

TOMAN, K. Tuberculosis: Detección de casos y quimioterapia. Preguntas e respuestas. OPAS/OMS, 1980. p.9-13. (Publicación cientifica. n. 392).

VALENZUELA, P.; LEPE, R.; PONCE , J.; VELASCO, M. Evaliación de la supervision indireta de la baciloscopia en Chile. sd. 9p. (mimeografado).

VIEIRA, L.T.M.; BEZEM, L.S. ABRAHĀO, J.S. Controle de Qualidade das baciloscopias realizadas pela rede de laboratórios de Saúde Pública do Estado de Santa Catarina no período de 1975 a 1987. Boletim do CNTC., v.2, n.2, jul./dez. 1988.

WORLD HEALTH ORGANIZATION. Diagnóstico. Techinical Report Series. n. 552, Wasghinton, p.313, 1974.

Recebido em maio de 2000

Aprovado em dezembro de 2001 